
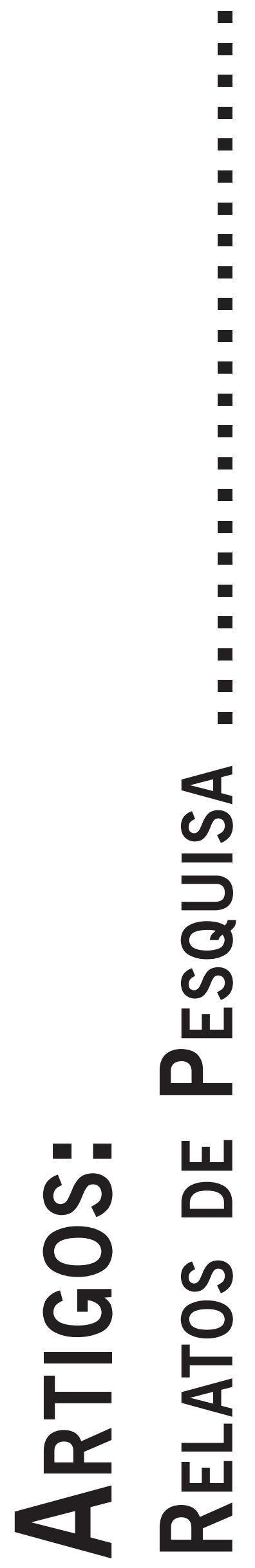


\title{
OS SIGNIFICADOS DA EXPERIÊNCIA INTERNA DA FORMAÇÃO PRESBITERAL: UMA ANÁLISE TEMÁTICA FENOMENAL
}

\author{
The Meanings of the Inner Experience of Priestly Formation: \\ a Phenomenal Thematic Analysis
}

Significados de la Experiencia Interna en la Formación Sacerdotal:

un Análisis Temático Fenomênico

Rafael Amorim de Paula

AleXsandro Medeiros do Nascimento

\begin{abstract}
Resumo: O presente estudo teve como objetivo descrever os significados da formação presbiteral em seminaristas católicos, considerando-os como gestalten discursivas resultantes de arranjos complexos de elementos de experiência interna, numa perspectiva idiográfica e fenomenal. Compreende-se que o seminário seja uma instituição total, criado a partir do Concílio de Trento e instrumento fundamental da modelagem da subjetividade dos futuros sacerdotes, e a formação presbiteral contempla os aspectos afetivo, intelectual e pastoral, sendo regida por orientações emanadas a partir das leis da Igreja. $\mathrm{O}$ foco do estudo recaiu, portanto, na experiência interna de seminaristas, a partir do impacto da formação na vivência dos sujeitos. Participaram do estudo 34 seminaristas (11 de Pernambuco e 23 do Rio Grande do Norte), oriundos dos três períodos do seminário maior (propedêutico, filosofia e teologia), os quais responderam um protocolo fenomenal. A análise do corpus discursivo foi realizada a partir dos pressupostos da análise fenomenal padrão, com apoio na técnica da análise temática. Os resultados anunciaram cinco categorias temáticas: Seminário: lugar de dificuldade/renúncia; Felicidade em ser seminarista; Reconhecimento/discernimento da vocação; Seminário: etapa/lugar de aprendizado; e, Masculinidade/valor. Os achados de pesquisa corroboraram aspectos da vida dos seminaristas anunciados por pesquisas anteriores, e revelaram elementos de tensão na vivência formativa.
\end{abstract}

Palavras-chave: Formação presbiteral; Significado; Experiência interna; Fenomenologia; Análise temática.

Abstract: The study aimed to describe the meanings of priestly formation in Catholic seminarians, considering them as discursive gestalten resulting from complex arrangements of elements of inner experience, in a phenomenal and idiographic perspective. The seminar is a total institution, created by the Council of Trent, and fundamental instrument of modeling subjectivity of future priests, and priestly formation includes the affective, intellectual and pastoral aspects, being governed by guidelines issued from laws of the Church. The focus of the study fell in the inner experience of seminarians, and in the impact of training on the experience of the subjects. 34 seminarians (11 from Pernambuco and 23 from Rio Grande do Norte) participated in the study, coming from the three periods of the major seminary (Propaedeutic, Philosophy and Theology), who answered a phenomenal protocol. The analysis of the discursive corpus was performed from assumptions of standard phenomenal analysis, with support in the thematic analysis technique. The results announced five thematic categories: Seminar: Place of difficulty/waiver; Happiness at being seminarian; Recognition/discernment of the vocation; Seminar: period/place of learning; and Masculinity/value. The research findings corroborated aspects of life of seminarians announced by previous research, and revealed elements of tension in the formative experience.

Keywords: Priestly Formation; Meaning; Inner Experience; Phenomenology; Thematic Analysis.

Resumen: El presente estudio tiene como objetivo describir los significados de la formación sacerdotal en seminaristas católicos, teniendo en cuenta como gestalten discursivas el resultado de una compleja disposición de elementos de experiencia interna, desde una perspectiva idiográfica y fenoménica. Se entiende que el seminario es una instituición totalizadora, creada a partir del Concilio de Trento, e instrumento fundamental de modelización de la subjetividad de los futuros sacerdotes, así como la formación sacerdotal contempla los aspectos afectivo, intelectual y pastoral, siendo regida por orientaciones que emanan de las leyes de la Iglesia. El enfoque del estudio recayó, por tanto, en la experiencia interna de seminaristas, a partir del impacto de la formación en la vivencia de los sujetos. Participaron en el estudio 34 seminaristas (11 de Pernambuco y 23 de Río Grande del Norte), oriundos de los tres períodos del seminario superior (propedéutica, filosofía y teología), los cuales responderán a un protocolo fenoménico. El análisis del corpus discursivo se realizó a partir de los presupuestos del análisis fenoménico estándar, con soporte en la técnica del análisis temático. Los resultados presentarán cinco categorías temáticas: Seminario: lugar de dificuldad/renuncia; Felicidad de ser seminarista; Reconocimento/discernimiento de la vocación; Seminario: etapa/lugar de aprendizaje; y, Masculinidad/ valor. Los resultados de la investigación corroborarán aspectos de la vida de los seminaristas ya anticipados por investigaciones anteriores, y revelarán elementos de tensión en la vivencia formativa.

Palabras-clave: Formación sacerdotal; Significado; Experiencia interna; Fenomenología; Análisis temática. 


\section{Introdução}

A literatura universal e a indústria cinematográfica vêm há algum tempo retratando questões relacionadas à sexualidade, ao desejo, aos conflitos psíquicos, às disputas de poder e reconhecimento que são postas em questão nas vidas de clérigos e religiosos, como também daqueles que aspiram ao estado clerical. Na literatura, poderíamos citar $O$ vermelho e o negro, do francês Stendhal; O Seminarista, de Bernardo Guimarães; Dom Casmurro, de Machado de Assis; O crime do Padre Amaro, do lusitano Eça de Queirós, entre outras obras. Na produção cinematográfica, além de alguns títulos citados acima que se tornaram filmes, temos o famoso seriado estadunidense Pássaros feridos, como também alguns filmes, como O Ritual e A Dúvida. Cada qual, desnuda nuances desses atores sociais, que apesar dos tons apelativos e vieses anticlericalistas que hoje no início do século XXI nos faz questionar e procurar entender aspectos da dinâmica psíquica desses sujeitos e os aspectos enlaçados na produção dessas subjetividades. Dessa maneira, é importante investigar a formação clerical e seus efeitos na vida psíquica. Embora a produção científica não seja, por enquanto, expressiva, e aparentemente focada apenas na Psicologia Social (Benelli, 2003; 2007a; 2007b) para esse locus de pesquisa, optou-se neste presente estudo por uma ancoragem teórica não somente a partir de uma perspectiva psicossociológica, mas fazer uso também, da perspectiva fenomenológica, em especial no tocante a abordagem da experiência interna em psicologia cognitiva (Heavey \& Hurlburt, 2008; Nascimento, 2008).

A formação presbiteral, englobando os aspectos afetivo, intelectual e pastoral, é atualmente regida por um conjunto de textos que compõe o discurso pastoral-normativo. O primeiro dentre eles é o Código de Direito Canônico, que norteia o governo da Igreja Católica, abrangendo da disciplina referente aos sacramentos, aos direitos e deveres dos fiéis e clérigos. Neste código, existe uma seção dedicada à admissão ao estado clerical, que regula as etapas da formação. Outros documentos importantes são a Ratio Fundamentalis Instituiones Sacerdotalis (Igreja Católica, 1970) e Optatam Totius (Igreja Católica, 1965) que trazem as diretrizes elementares para a formação dos futuros sacerdotes, e mais recentemente Pastores Dabo Vobis (1992) do Papa João Paulo II (1992), e dois da Congregação para a Educação Cristã que são Instrução sobre os critérios de discernimento vocacional acerca das pessoas com tendências homossexuais e da sua admissão ao Seminário e às Ordens Sacras (Igreja Católica, 2005) e Orientações para a utilização das competências psicológicas na admissão e na formação dos candidatos ao sacerdócio (Igreja Católica, 2008).

Entender que a dinâmica institucional é extremamente importante para a compreensão da modelagem da subjetividade do seminarista, já é um passo dado, principalmente quando entendemos o Seminário como uma
Instituição Total (Benelli, 2007a; 2007b), modelo de instituição amplamente estudado por Erving Goffman (1974), encontramos diversos aspectos dele que corroboram essa perspectiva. Os seminários, como instituição total, são estabelecimentos fechados nos quais os indivíduos vivem em regime de internação, onde os internados convivem em tempo integral, geralmente sendo um número relativamente grande de pessoas que compartilham o espaço desses estabelecimentos. Essa modalidade de instituição funciona como local de residência, trabalho, lazer e espaço de alguma atividade específica, tal como: terapêutica, correcional, educativa etc. Comumente existe um grupo dirigente que exerce o gerenciamento administrativo no cotidiano da instituição. Em relação a esse processo de fechamento da instituição total Goffman (1974, p. 16) diz que: "Toda instituição conquista parte do tempo e do interesse de seus participantes e lhes dá algo de um mundo, toda instituição tem tendências de fechamento". Benelli (2006) propõe que no bojo institucional da formação presbiteral, é possível um estudo dos diversos fenômenos que são produzidos nesse lugar, que permitem uma valiosa compreensão da formação de pessoas, como também "seria possível entender como nessas instituições se produz e reproduz a subjetividade daqueles que as compõem, tanto internados quanto dirigentes" (Benelli, 2006, p. 148).

Levando-se em conta a natureza dual da subjetividade humana em que enlaçam-se os domínios psicológico e fenomenal relacionado aos estados qualitativos de vivência consciente da experiência interna (Chalmers, 1996, 2010; Kriegel, 2006; Heavey \& Hurlburt, 2008; Nascimento, 2008; Velmans, 2009; Schneider, 2012; Nascimento, Griz, \& Vieira, 2013), sendo tal fonte interna o motor da agência humana, diante dessas considerações se faz a seguinte pergunta de pesquisa: "Como o seminarista católico experiencia e significa sua formação presbiteral durante o período de seminário?”. A hipótese assumida aqui é a de que a formação presbiteral acontece intimamente relacionada a um modelo institucional que é modelador das subjetividades daqueles que vivem na instituição seminário, e que por sua vez tem ressonância na vida psíquica. Logo, o fazer parte de uma instituição no percurso formativo-religioso desses sujeitos implicaria uma experiência singular e constituinte do seminarista católico que implicaria na apreensão da sua vivência do seminário, isto por sua vez, constituiria a experiência interna da formação presbiteral a partir do seminarista.

Dessa maneira, surge a percepção de que se faz necessário um estudo de caráter intrinsecamente idiográfico, qualitativo e fenomenal que tenha por meta compreender como os seminaristas católicos vivenciam essa experiência formativa a partir dos impactos que a formação presbiteral exerce sobre as subjetividades. Essa necessidade emana de que, predominantemente, os estudos referentes à formação presbiteral estão situados na esfera da Psicologia Social, em alguns momentos, dialogando com a perspectiva clínica. Embora existam promissores e re- 
levantes achados das investigações já realizadas, no que tange a experiência interna e demais temáticas da Psicologia Cognitiva relacionados aos estudos sobre formação presbiteral há um significativo hiato que evoca investigações que as explorem. Nisso há também a necessidade da aplicação de diversas metodologias que acorram a emergência dessas vivências.

A formação presbiteral, em especial os sujeitos seminaristas, tem sido recentemente alvo de pesquisas na literatura científica, em especial na nacional (Benelli, 2007a, 2007b; Meschiatti, 2007; Spiess, 2011, 2012; Baungart \& Amatuzzi, 2013; Santos, 2016). Além do mais esse estudo propõe uma investigação da formação presbiteral na interface dos estudos da consciência, área que possui produção insuficiente no Brasil, conforme pontua Nascimento (2008), e acrescenta relevância para a questão proposta nesse trabalho, sendo seu objetivo primordial mapear e descrever num enfoque fenomenal os aspectos de significado que compõem a vivência do seminarista católico na constituição da sua experiência interna durante seu itinerário formativo-religioso.

\section{O Seminário Católico}

O seminário católico tem sua origem no Concílio de Trento (1545-1563), no período da Contrarreforma. Este concílio, um dos mais longos da história da Igreja, foi o que mais emitiu decretos e documentos orientando diversos aspectos da Fé católica, em especial aqueles questionados por Martinho Lutero. Procurou responder a questões no tocante a vida dos seus ministros, regulou por definitivo a disciplina do celibato dos padres, apesar dos protestos de muitos bispos que viam que na prática era ineficiente e certificou-se da preparação moral e intelectual dos aspirantes ao estado clerical, sendo o seminário seu principal dispositivo.

O Concílio de Trento ofereceu uma identidade católica para a Europa, chegando ao apogeu nos séculos XVI e XVII. Sua autoridade só foi ameaçada pelos abalos na Igreja gerados durante a Revolução Francesa, os quais inquietaram a religião e os regimes absolutistas. Diante das consequências desta e da conseguinte perda dos territórios pontifícios, a campanha católica de resguardar a Igreja se deu na realização do Concílio Vaticano I (1869-1870), o qual, embora não tenha cumprido todos os seus objetivos, chegou a declarar o dogma da Infalibilidade Papal, objetivando garantir a unidade da Igreja apesar das contestações à autoridade pontifícia (Meschiatti, 2007).

A palavra seminário tem sua origem no latim seminarium, proveniente de semen, seminis, isto é, "semente". Seu sentido originário era o de viveiro de plantas, onde as sementes se desenvolvem e como mudas são plantadas no solo. Percebe-se o caráter que o seminário adquire: lugar de crescimento, de educação. Por muito tempo os seminários e casas religiosas se ocuparam da Educação, a própria palavra deriva seu significado do latim, tanto educare, no sentido de transmitir conhecimentos quanto educere, ato de fazer desabrochar potencialidades, desenvolvendo a personalidade do indivíduo, lugar não somente de se desenvolver, mas que cumpre uma finalidade (Benelli, 2008).

Ao falar em seminário é importante chamar à atenção a distinção entre seminário menor e seminário maior. O seminário menor é aquele que acolhe os candidatos à vida sacerdotal que ainda não concluíram o Ensino Médio. O seminário maior acolhe os candidatos ao sacerdócio. O seminário maior é marcado por três períodos: propedêutico, filosofia e teologia. O propedêutico tem a duração de um ano, e pretende ser um período de formação no qual a dimensão espiritual é aprofundada, como também um momento de maturação e preparação para os anos futuros de formação. Durante o período de formação o seminarista fará os cursos de filosofia (período mínimo de dois anos) e teologia (quatro anos), formação que pode ser feita no próprio seminário ou externamente em faculdades, geralmente vinculadas a Igreja Católica.

O seminário pode ser compreendido como uma instituição total (Benelli, 2007c; Goffman, 1974). Dessa forma complexa é a trama das relações subjacentes à experiência de ser seminarista quando inserido na dinâmica institucional e o movimento e tensões entre indivíduo e instituição e os enquadres sofridos pelos indivíduos (Rocha, 1991; Benelli, 2003, 2007a; Baungart \& Amatuzzi, 2013). A "clausura" que de certa maneira o seminário impõe aos seminaristas coloca-os numa situação de indivíduos internados num estabelecimento onde residem com um grande número de outros seminaristas em situação semelhante. O seminário compreende lugar com várias funcionalidades: moradia, estudo, trabalho, formação e lazer (Benelli, 2007a).

A natureza dessa instituição implica ser um "dispositivo organizado de modelagem subjetiva, tanto por seus discursos e por suas práticas, quanto pela articulação (sintonia ou contradição) desses dois aspectos" (Benelli, 2006, p. 148). Enquanto instituição total encontra diversas semelhanças inclusive com os conventos - matriz que inspirou o Concílio de Trento no tocante a disciplina dos seminários. Nessa perspectiva, este modelo de instituições pretende "o controle do tempo, dos corpos e a instalação de um poder polimorfo. Fazem funcionar um poder polivalente, microfísico, que não é essencialmente localizável em um polo centralizado e personalizado, mas que é, principalmente, difuso, espalhado, minucioso, capilar" (Benelli, 2006, p. 152).

\section{A Formação Presbiteral a partir da Igreja Católica}

"Dar-vos-ei pastores segundo o Meu coração" (Cf. Jr. $3,15)$, com esse trecho do profeta Jeremias a exortação 
apostólica Pastores Dabo Vobis (1992) do Papa João Paulo II (1992) traz um aspecto nuclear da dinâmica vocacional e das expectativas lançadas pela instituição sobre aqueles que almejam a vida sacerdotal: o de Pastor. A figura sacerdotal é emblematicamente relacionada ao Pastoreio. O padre (pai, em latim) é colaborador do ministério episcopal, isto é, colaborador do bispo e por sua vez com ele exerce seu ministério com uma porção da Igreja.

A formação dos futuros presbíteros é tida como umas das tarefas de maior delicadeza e importância para a evangelização. Além daquelas preocupações que atentam para a santificação pessoal e formação intelectual, uma que tem sido alvo da atenção da Igreja é no tocante a sexualidade. Na última década, alarmante foi a veiculação pelos meios de comunicação, dos casos de abuso de menores por parte de clérigos, nos Estados Unidos, na Europa e tantos outros lugares que irromperam.

No ano de 2008, a Congregação para a Educação Católica, até então responsável pela formação presbiteral, emitiu o documento Orientações para a utilização das competências psicológicas na admissão e na formação dos candidatos ao sacerdócio (Igreja Católica, 2008) na qual indica a contribuição da psicologia e o quanto pode oferecer aos formadores dos seminários, não somente um diagnóstico e a eventual indicação de terapia dos distúrbios psíquicos, mas também possibilitar o desenvolvimento das qualidades humanas requeridas para o exercício do ministério presbiteral. O documento (n. 2) enumera um elenco de qualidades para o ministério: sentido positivo e estável da própria identidade viril; capacidade em relacionar-se de modo amadurecido com outras pessoas e grupos de pessoas; sólido sentido de pertença à hierarquia institucional; liberdade em entusiasmar-se por grandes ideais e a coerência em realizá-los nas ações de cada dia; coragem em tomar decisões e de permanecer fiel a elas; conhecimento de si, das suas qualidades e limitações, integrando-as num apreço de si diante de Deus; a capacidade de se corrigir; gosto pela beleza entendida como "esplendor da verdade" e a arte em reconhecê-la; estima pelo outro e que leva ao acolhimento; e, capacidade do candidato em integrar, segundo a visão cristã, a sua sexualidade, inclusive na consideração da obrigação do celibato.

Outro documento importante é a Instrução sobre os critérios de discernimento vocacional acerca das pessoas com tendências homossexuais e da sua admissão ao Seminário e às Ordens Sacras (Igreja Católica, 2005), na qual faz uma breve abordagem da moralidade dos atos homossexuais e aponta as questões referentes ao ingresso de homossexuais no seminário e sua posterior ordenação. O documento pondera em última instância a necessidade de verificar a idoneidade dos candidatos e caso necessário aponta a relevância de um profissional de psicologia que contribua no discernimento do caso.

Nas Diretrizes para a Formação dos Presbíteros da Igreja no Brasil (2010), a Conferência Nacional dos Bis- pos do Brasil - CNBB (2010) aponta as dimensões para a formação do seminarista, a saber, Humano-afetiva - visa capacidade de autoconhecimento equilibrado, com exclusão de percepções distorcidas, e a resistência às tensões e provas a que a vida submete toda pessoa; Comunitária - a vida de comunidade, iniciada na casa de formação, deve continuar e encontrar sentido na vida do presbítero para dar à Igreja e ao mundo; Espiritual - se desenvolve pela oração e participação nos sacramentos e também pelo exercício da vida cristã e da caridade pastoral, que se realiza no interior da comunidade do Seminário através da participação na vida de outras comunidades cristãs e de engajamentos pastorais; Pastoral-missionária - deve ser norteada por uma metodologia que respeite, em cada experiência, os critérios de adequada iniciação, cuidadosa inserção, devido engajamento, e gradual responsabilidade por serviços ministeriais; e, Intelectual - formação intelectual consistente para o pastor para que ele compreenda de forma adequada a realidade humana em que vive e que possa interpretá-la à luz da fé, discernindo as linhas de ação do seu próprio ministério.

\section{A Experiência Interna e a Formação Presbiteral}

A palavra experiência é cara à psicologia e à fenomenologia pela sua complexa relação com a vida psíquica e seus desdobramentos na realidade dos sujeitos. O termo experiência, do latim experientia, significa o que foi retirado (ex-) de uma prova ou provação (perientia) $\square$ um conhecimento empírico obtido no mundo, isto é, em contato sensível com a realidade. A experiência relacionase com o que se vê, com o que se toca ou sente, mais do que com o pensamento (Amatuzzi, 2007). Experienciar é precisamente captar o sentido daquilo que se procura investigar, emitindo uma circunspecção sobre o encontrado (Gaspar \& Mahfoud, 2006), consiste certamente em "provar" alguma coisa, mas coincide, sobretudo, com o juízo dado a respeito daquilo que se prova. Seguindo-se este insight primordial, vê-se em Giussani (2000) que a pessoa é, antes de tudo, consciência. Assim, o que caracteriza a experiência não é tanto o interfaciar mecanicamente a realidade estabelecendo relações, mas a compreensão emergente desta atividade, a descoberta do seu sentido, a razão do sentido das coisas experienciadas (Giussani, 1997; 2000; Gaspar \& Mahfoud, 2006).

É relevante apontar que o termo "Consciência” é polissêmico e por vezes impreciso, que se alude a vários tipos de fenômenos como a habilidade para discriminar, categorizar e reagir a estímulos ambientais; a integração da informação através de um sistema cognitivo; a capacidade de relatar a ocorrência de estados mentais; a habilidade de um sistema para acessar seus próprios estados internos; o foco da atenção; o controle deliberado do comportamento; a diferença entre sono e vigília, etc. (Chalmers 2010; 1996; Nascimento, 2008). 
A complexidade da experiência está profundamente arraigada pela consciência, é através dela que o conhecimento sensível do que nos cerca é apreendido, em especial pela sua singularidade. Tudo o que sentimos, pelo tato, pela visão, audição, como também os aspectos subjetivos da experiência constituem uma complexa trama de modos de significar e nomear; da mesma forma que o intenso fluxo de pensamentos que vertiginosamente emergem do sujeito. Esta fenomenologia de si mesmo é tão profunda e intangível que às vezes parece ilusória. Ainda assim, parece haver algo para a fenomenologia do self, o qual ainda é muito difícil de definir (Chalmers, 1996).

Embora Chalmers (1996) reconheça o considerável progresso no conhecimento da mente pelas neurociências e ciências cognitivas, alega que não alcançaram ao que alcunhou o "problema difícil da consciência": por que o processamento de informação que realizamos, isto é, discriminar, reunir e relatar a informação, é seguido de uma vida interna que experienciamos? (Borgoni, 2011).

Chalmers (1996) pondera que a relação entre mente e consciência é atravessada por dois conceitos. O primeiro é o conceito fenomenal da mente. Este é o conceito da mente como a experiência consciente, e de um estado mental como um estado mental consciente experiente. Para Chalmers esta dimensão é a mais intrigante da mente e sobre a qual pretende empreender uma reflexão, todavia, essa perspectiva não exaure a complexa questão do mental. O segundo é o conceito psicológico da mente. Este é o conceito de mente como base causal ou explicativa para o comportamento. Enquanto o primeiro, fenomenal, está baseado na experiência da mente, o segundo debruça-se no que a mente faz (Chalmers, 1996; Borgoni, 2011).

A experiência é um fenômeno interessante. Essa experiência se manifesta em várias modalidades (Chalmers, 1996) e cada uma possui sua singularidade, algumas serão citadas a seguir. As experiências visuais possuem um conjunto de sensações e percepções que constituem uma experiência do mundo que tornam a experiência interna rica e beira a inefabilidade. As experiências auditivas embora diferentes das visuais, em especial as experiência da música e do discurso, e as quais podem desencadear uma emoção, como é o caso de escutar uma peça musical. As diversas sensações corpóreas, de quente e frio, a percepção de dor constituem modalidades da experiência interna.

Contudo, algumas experiências de ordem cognitiva chamam a atenção pela riqueza que conferem à experiência. As imagens mentais constituem uma experiência, na qual são formadas imagens sem o auxílio de uma percepção direta da realidade. O pensamento consciente é um intricado fluxo de conteúdos, sensações e percepções nas quais existe uma contínua permuta de conteúdo que figura da experiência. As emoções, outra modalidade, são associações de experiências; ao relatar a emoção o sujeito recorre a figuras de linguagem, elementos perceptivos, imagens mentais a fim de falar sobre aquilo que ele próprio sente. E por fim, o senso de self (o senso de eu, de mim), talvez a experiência mais complexa para ser descrita, e que, no entanto, a mais fundante da experiência, sobretudo porque parece tratar de algo como um pano de fundo, a consciência de si mesmo - a autoconsciência, como auto-apreensão interna e qualitativa de auto-aspectos do self (Chalmers, 1996).

Todavia o acesso à experiência interior é complexo e nem sempre os conteúdos referentes a ela estão a nível consciente, isto é a experiência existe, mas é percebida tenuamente, experiência dita prístina segundo Hurlburt (2009), antes de qualquer apreensão consciente voluntária. Isto também implica que o conhecimento da experiência interna é importante e contribui para a compreensão da experiência imediata (Heavey \& Hurlburt, 2008; Hurlburt, 2009), havendo um papel expressivo da linguagem em ancorar em categorias semântico-conceituais tais feixes complexos de elementos da experiência interna (Carruthers, 2002), favorecendo a emergência de um sentido possível à mesma, sentido racional e passível de compartilhamento discursivo e intersubjetivo, sumário objetivante que contorna a experiência dando-lhe concretude em seu ancoramento à noções da psicologia folk compartilhadas na cultura de pertença (Morin, 2005; Nascimento, 2008).

Nestas bases teóricas, tornar-se-ia legítimo investigar a malha cognitiva e fenomenal que constrói a formação presbiteral como objeto na/da/para consciência do presbítero em formação, não sendo, todavia o foco investigativo definido aqui. Assume-se que a vivência consciente da formação presbiteral compõe-se de vários elementos dentre os tipologizados por Chalmers (1996) como visualizações internas (imagens mentais), elementos discursivos (fala interna), afetos, autoconsciência e outros, os quais precipitam-se numa gestalt de onde emerge um sentido possível da experiência interna para cada indivíduo consoante ao objeto em tela, resultado este de extração de sentido formalizável em discurso escrito a posteriori. Sendo este justamente o foco da investigação presente, a saber, os campos de significados resultantes da experiência interna, a pesquisa buscou mapear e descrever os significados da formação presbiteral em seminaristas católicos, como gestalten discursivas resultantes de arranjos complexos de elementos de experiência interna, numa perspectiva idiográfica e fenomenal, numa mirada analítica que buscou a tipologização de tal experiência em torno de temas ou categorias temáticas.

\section{Método}

\section{Participantes}

Esse estudo foi conduzido em dois Seminários Maiores católicos: um no estado de Pernambuco e outro no Rio Grande do Norte. Foram 34 seminaristas (11 de Pernambuco e 23 do Rio Grande do Norte) que participaram da 
pesquisa, contudo um dos seminaristas solicitou a retirada do protocolo do corpus de pesquisa, no qual foi atendido. Os seminaristas estavam distribuídos nas seguintes etapas da formação presbiteral, do início à conclusão da formação: Propedêutico (22\%), curso de Filosofia (54\%) e curso de Teologia (24\%). As idades variaram de 17 a 44 anos, com idade média de 23,8 anos ( $\mathrm{DP}=5,02)$.

\section{Instrumento}

Utilizou-se o Relato Fenomenológico, um instrumento fenomenal que possui a seguinte pergunta indutora: "Como é ser seminarista para você?". O objetivo do relato é capturar a vivência dos participantes da pesquisa e elementos que comuniquem aspectos da experiência formativa de um seminarista.

\section{Procedimentos}

Após a liberação da pesquisa por parte do Comitê de Ética da Universidade Federal de Pernambuco ( $\mathrm{n}^{\circ}$ de protocolo 405/11) e das permissões por escrito, através de Carta de anuência dos reitores dos seminários investigados, o pesquisador se apresentou aos participantes em potencial no próprio ambiente de investigação (o seminário) a fim de convidá-los a compor a amostra de participantes do estudo proposto; após a leitura, esclarecimento sobre os objetivos do estudo e assinatura do Termo de Consentimento Livre e Esclarecido deu-se a aplicação do protocolo da pesquisa. Foi dado a cada participante uma folha na qual constava a pergunta indutora, a qual o mesmo pode responder, escrevendo na folha, sem delimitação de tempo para a pergunta.

\section{Análise dos dados}

No tocante ao método fenomenológico compreendemos, enquanto instrumento de análise lógica e de confronto à realidade, que ele pretende apreender os significados revelados por um sujeito sobre sua experiência (Castro \& Gomes, 2011). Embora seja um método originalmente filosófico, resguardadas as diferenças epistemológicas entre filosofia e psicologia, sua evolutiva transposição para a psicologia implicou em variações quanto ao processo de investigação (Moreira, 2004; Giorgi, 2006; Castro \& Gomes, 2011; Feijoo \& Mattar, 2014). Enquanto método requer um instrumento, e certamente o mais empregado na maioria das pesquisas em psicologia seja a Entrevista semi-estruturada, na qual o pesquisador fenomenólogo faz uso de uma pergunta indutora que dispara o acesso a experiência do sujeito (Moreira, 2004), entretanto outros dados gerados em observações, documentos (audiovisuais, por exemplo), ou até mesmo registro escrito da experiência vivida são empregados pertinentemente nas pesquisas de corte fenomenológico (Moreira, 2004; Nascimento, 2008; Castro \& Gomes 2011). O mais relevante para a pesquisa de viés fenomenológico como admoesta Moreira (2004) não estará prioritariamente no instrumento, mas na primazia da experiência. Embora o método fenomenológico tenha características flexíveis, em especial no tocante as investigações científicas, isso não implica em dizer que todas as variações sejam legitimas. Essas variações deverão estar perfiladas ao fenômeno investigado e coerência ao método (Giorgi, 2006).

Fiéis a estes critérios norteadores e seguindo a metodologia fenomenológica padrão (Boemer, 1994; Cott \& Rock, 2008; Nascimento, Griz \& Vieira, 2013), a análise temática consistiu das seguintes etapas, sumarizadas por Cott e Rock (2008): 1. Os protocolos foram digitados e lidos cuidadosamente várias vezes para promover a compreensão do relato da experiência dos seminaristas; 2. Frases marcantes, declarações ou frases que se referem aos efeitos subjetivos da experiência dos seminaristas foram extraídas dentro de cada protocolo; 3. Declarações marcantes extraídas com o mesmo significado foram organizadas de forma que se manteve a essência fundamental da experiência de cada participante, assim, permitindo o desenvolvimento de temas constituintes dentro de cada protocolo; 4. Estes temas constituintes foram então analisados através de protocolos e os temas aglutinados em torno do mesmo significado foram organizados em temas abrangentes constituintes; 5 . Os temas abrangentes constituintes foram avaliados para determinar se alguma sobreposição de temas abrangentes constituintes poderia ser recolhida; e, finalmente, 6. Os temas abrangentes constituintes foram integrados em um parágrafo final para formar uma definição estrutural fundamental que capturou os aspectos essenciais da experiência da formação presbiteral.

\section{Resultados e discussão}

A análise fenomenológica revelou cinco categorias temáticas emergentes da experiência da formação presbiteral, as quais serão descritas e interpretadas na sequência.

\section{Seminário: lugar de dificuldade/renúncia}

O seminário é apontado como um lugar de dificuldade, embora em alguns momentos aceito com resignação, pois aceita-se que na vivência da formação presbiteral no cumprimento da vocação "Não se trata de uma vida só de flores, as dificuldades fazem parte da caminhada vocacional" (Protocolo 20, Propedêutico). A ideia é de que a formação é um caminho árduo que implicou renúncia de vários elementos que eram aspectos importantes da vida anterior ao seminário: renúncia da família, pri- 
meiro objeto de amor; da namorada, abdicação de uma relação afetiva com alguém do sexo oposto; renúncia dos sonhos e projetos, os quais individualizam o sujeito. O seminarista percebe que abdica de uma zona de conforto e afeto em troca, talvez inesperada, de uma vivência permeada de tensão - a vida no seminário, nesta “(...) que é uma vida desafiadora, cheia de obstáculos, de perigos, de medos, de sonho, de preocupações, de desejos, de descobertas, de dores, de dúvidas, de angústias... e de tantas outras coisas negativas que poderia lhes dizer" (Protocolo 25, Propedêutico).

A formação parece estar permeada por uma tensão, a qual o seminarista precisa lidar; palavras como: árdua, renúncia, se entrelaçam com missão, caminho, busca. Parece que essa vivência é necessária para se chegar a um "bem maior", contudo, experienciar essa realidade pode deixar "marcas" como revelam os dados fenomenais. Aqui apresentam-se elementos discursivos a partir das palavras e figuras de linguagem que possibilitam a emergência de um sentido possível da experiência interna do que o sujeito sente (Chalmers,1996). Essa questão aponta para um estado, mais ou menos caracterizado, em que o sujeito é capaz de versar de forma racional com o seu ambiente de alguma forma, e por isso reverbera em um tipo particular de consciência (Chalmers, 2010).

As relações estabelecidas entre os seminaristas, os conflitos interpessoais, a separação da família, a renúncia ao namoro e à sexualidade, e de certa forma o abandono de outros projetos pessoais e profissionais em detrimento da formação presbiteral apontam para experiência clara na vida de um seminarista (Benelli, 2003; 2006). Os seminaristas apontam que continuam no seminário por razões de fé, e não obstante todos os entraves, "insistem na sua vocação ao sacerdócio, sem deixar de indicar a importância do fator acadêmico em sua decisão de prosseguir na formação" (Benelli, 2003, p. 228). A própria dinâmica do funcionamento do seminário, o processo de vigilância da equipe formadora, quanto entre os próprios seminaristas, a não vivência da autonomia e liberdade (Baungart \& Amatuzzi, 2013; Benelli, 2003; 2007a; 2007b) são propiciadores dessa experiência. Fica apontado que a experiência interna destes seminaristas fica atrelada a experiência de si mesmo, da mesma forma que suas emoções, como também da experiência religiosa aglutinada à instituição e que perpassa nas trajetórias e nas representações que seminaristas fazem sobre sua própria vocação (Spiess, 2012).

\section{Felicidade em ser seminarista}

O seminarista se percebe como escolhido, eleito. Vê o estado sacerdotal como um dom, algo a ser almejado. Contrapõe os momentos de dificuldade com os de alegria, caminham lado a lado a percepção dos aspectos sombrios e difíceis da vocação, com a valoração positiva da experiência, como realçado pelo seminarista em seu testemu- nho: "Mais [sic] o seminário não só tem esse lado escuro (...) SEMINARISTA É BOM DEMAIS" (Protocolo 25, Propedêutico; grifos do participante). Alguns elementos da vivência formativa como a fraternidade e a oportunidade de estar se preparando são vistas como positivas, como expresso no excerto:"Mas também a [sic] momentos de alegrias, sejam elas proporcionados [sic] pelo seminário enquanto instituição, seja pela fraternidade." (Protocolo 10, Filosofia).

Embora o seminarista perceba o seminário enquanto lugar de renúncia, também existe a percepção de aspectos positivos, não há somente "um lado escuro". Esse relato mostra que também eles encontram modos de significar positivamente a sua experiência e, quiçá empreguem recursos a fim de obter satisfação. No entanto, representa a sua experiência na satisfação em estudar, rezar e trabalhar na esteira do pensamento beneditino ora et labora (do latim: Reza e trabalha). Benelli (2007a) coloca que em meio aos conflitos vivenciados no seminário, os seminaristas encontram estratégias a fim de poderem lidar com as pressões advindas do meio, seriam as "virações". No tocante a isso a experiência revela como "provar" alguma coisa, compreender, descobrindo o sentido das coisas (Giussani, 1997; Gaspar \& Mahfoud, 2006). Contudo, os dados fenomenais não possibilitaram distinguir até que ponto essas afirmações emergem de sua real experiência, ou se seria uma defesa, a fim de se resguardar tendo em vista que a permanência no seminário é fundamental ao menos para ser ordenado padre.

\section{Reconhecimento/discernimento da vocação}

O seminarista reconhece sua vocação e enxerga o seminário como lugar aonde compreende e amadurece seu chamado. O seminário, "viveiro" de sacerdotes, é também percebido como instância moldadora da própria vocação. O seminarista não pretende ser seminarista para sempre, realça que sua vocação não é a de ser seminarista, sua vocação é ser padre; ser seminarista é uma condição circunstancial, provisória, significado graficamente testemunhado pelo seminarista:"Todo ideal busca sua realização. Para mim é muito claro de que o ser seminarista não é Meu ideal, Mas sim, o sacerdócio. A vocação não é ser seminarista, Mas antes, ao sacerdócio." (Protocolo 13, Teologia). O significado da formação enquanto transição a outro estado, e de auto-ausculta nesse processo é emblematicamente enfatizado pelos seminaristas, como vê-se no excerto do relato fenomenológico do participante: "Ser seminarista é o estar neste processo que Me leva ao Meu ideal: O sacerdócio." (Protocolo 13, Teologia). Firma-se para o seminarista o senso de ser o seminário lugar sobretudo de encontro consigo mesmo, com suas mais caras aspirações, humanas e espirituais, e lócus de ajuizamento de sua verdadeira vocação, processo de tomada de juízo autêntico, tanto para os que se percebem verdadeiramente 
vocacionados, quanto para os que se percebem destinados a vivência da fé nos domínios laicos, como expresso no excerto seguinte em que o seminarista ajuíza a formação presbiteral: "É fase, é discernimento! Estou saindo da instituição por descobrir que enquanto seminarista, não poderei ser um bom padre.” (Protocolo 23, Propedêutico). Além de um reconhecimento da vocação, também há o contínuo processo de avaliação que causa desconforto, a identificação com a figura do sacerdote, em especial diante de aspectos positivos e negativos identificados na figura do padre, e o fato de que a vocação, pela sua complexidade, requer não somente um discernimento subjetivo (Baungart \& Amatuzzi, 2013).

Na exortação apostólica Pastores Dabo Vobis (1992, n. 10), João Paulo II pontua acerca do discernimento como função do espírito de operar distinções entre bem e mal, entre sinais de esperança e ameaças, recaindo sobretudo sobre os aspectos positivos desta vivência de formação, dado que na formação dos futuros sacerdotes não se aspira tratar exclusivamente de "acolher os fatores positivos e de rejeitar frontalmente os negativos. Mas tem-se de submeter os próprios fatores positivos a um atento discernimento, para que não se isolem uns dos outros nem entrem em oposição entre si, absolutizando-se e combatendo-se mutuamente”. Da mesma forma deve-se auscultar os fatores negativos, na possibilidade de neles "ocultar-se algum valor que espera ser liberto e reconduzido à sua verdade plena”.

O próprio seminarista coloca em questão sua vocação em especial quando percebe os elementos positivos e negativos presentes na instituição, enquanto que o seminário denota como uma "máquina de vigiar", discernir e julgar a "vocacionalidade" do seminarista (Benelli, 2007b; 2007c). Esse aspecto revela um processo da consciência, sendo a experiência interna indiciadora de aspectos do Self e que promovem um aumento dos níveis de autoconsciência (Chalmers, 1996; Nascimento, 2008). De uma postura ingênua passa para uma atenta e consciente da sua experiência e assim repensa sua própria vocação (Benelli, 2003; 2007a). A questão da escolha vocacional está arraigada na própria identificação e subjetivação do ser padre, tanto que a formação pretende alçar esse homem natural numa abertura à transcendência, e a partir daí desenvolver a personalidade do religioso (Benelli, 2007a), embora haja um processo de inculcação do projeto vocacional a ser assumido pelo candidato ao presbiterado (Spiess, 2011; 2012).

\section{Seminário como etapa/lugar de aprendizado}

A formação presbiteral é compreendida como algo importante e relevante durante a permanência no seminário, sua importância também é salientada quando considerado o exercício futuro do ministério presbiteral, torna-se inteligível portanto, a urgência de uma vivência signifi- cante deste período, conforme expressa no excerto deste seminarista: "(...) o seminario [sic] é apenas uma etapa de formação e tenho que aproveita-la." (Protocolo 2, Filosofia). A pastoral, a vida comunitária, o cultivo da espiritualidade e da santidade, também são elementos que integram a formação na perspectiva do seminarista, aspecto esse que parece interiorizado pela ênfase que é dada por aqueles que dirigem o seminário nas diversas experiências formativas do período, instâncias de um aprendizado e modelação interior imprescindíveis à concretização do sonho do sacerdócio, como expresso no excerto: "Ser seminarista é uma etapa da minha vida necessária para alcançar o meu desejo vocacional de ser padre." (Protocolo 11, Teologia). Dessa forma, a experiência não é demarcada aridamente pelas relações com a realidade, mas a apreensão emergente deste período formativo, possibilita a descoberta do seu sentido, a razão do sentido das coisas experienciadas (ver Giussani, 1997; 2000; Gaspar \& Mahfoud, 2006).

O seminário é fundamentalmente uma instituição educacional e com propósito objetivo: formar padres. $\mathrm{Na}$ experiência do seminarista católico existe uma tônica em relação a importância dos estudos, no entanto também existe uma consciência de que essa formação é circunstancial, isto é, ela está determinada a ter um tempo de duração, mesmo que longo (Baungart \& Amatuzzi, 2013). O aprendizado não é circunscrito à formação acadêmica, também é posto o aprendizado pastoral, como também a própria experiência de passar pelo seminário carrega um aprendizado subjetivo. Segundo a Igreja, as conjunturas atuais e os desafios da evangelização exigem padres notadamente qualificados e competentes. Afinal serão eles que participarão mais de perto como colaboradores de seus bispos, assumindo trabalhos pastorais sempre mais gerais e complexos, junto com ações cada vez mais amplas no interior e fora da diocese. Diante do grande encargo pastoral é indubitável que do futuro presbítero exija-se uma competência teológica e garantido conhecimento doutrinal (CNBB, 2010). O aspecto formativo é posto em alta consideração pelas orientações da Igreja e sua relevância não está concernente somente ao aspecto pastoral, mas no diálogo com a cultura laica. Benelli (2007b, p. 103) coloca que a formação presbiteral "organiza-se como um longo 'período de prova', de exame, um longo escrutínio realizado pela equipe de formadores e pelos próprios candidatos, relativo à idoneidade do sujeito e à autenticidade da vocação".

\section{Masculinidade/valor}

A masculinidade é afirmada e associada à dimensão do valor. O seminarista é um homem de palavra, de integridade; os aspectos relativos a hombridade são colocados em relevo, como expresso graficamente pelo excerto seguinte, no qual coteja-se o período no seminário como 
um período de fortalecimento e crescimento interior com vistas ao seminarista"ser homem, homem de palavra, homem de caráter, homem de boa fé" (Protocolo 24, Propedêutico). Os atributos do presbítero futuro estão em gérmen no seminarista, e todo esforço da formação presbiteral é o cultivo destes atributos do verdadeiro homem, seus caracteres morais, éticos, e valores, para que aflorem e constituam seu caráter em definitivo, como expresso no excerto:"Ser seminarista é ser um sacerdote em potência, onde deve-se viver como um padre, vivendo a humidade [sic], a castidade, a obediência e sobretudo o amor a Deus, ao povo de Deus e a santa igreja de cristo [sic]" (Protocolo 29, Propedêutico), caráter este, condição sine qua non para que "um dia chegue a ordenação, e possamos ser homens felizes" (Protocolo 29, Propedêutico).

Essa categoria traz um elemento que perpassa a vida do seminarista católico; deste é solicitado à entrada no seminário adotar a disciplina do celibato em vista que após a ordenação sacerdotal isto será exigido dele. A própria tensão e discussão na qual o celibato é posto coloca a questão sempre em cheque, e a qual a Igreja opta por afirmar a disciplina do celibato. A expressão da sexualidade está no cerne do discurso a respeito da masculinidade, contudo existem outras vias pelas quais a masculinidade é afirmada e surgem outras formas de masculinidades e de identidade (Spiess, 2011). O Catecismo da Igreja Católica, no §1577 invoca que somente um varão, isto é, somente um homem pode receber validamente o sacramento da ordem. Da mesma forma na perspectiva eclesiástica o sacerdote é configurado a Cristo e é requisitado dele a figura da paternidade espiritual (Igreja Católica, 2003). Diante da questão das críticas ao celibato, o Papa Paulo VI escreve a carta encíclica Sacerdotalis Caelibatus (1967) na qual afirma no n. 78 a ascética viril do presbítero, pois "a vida sacerdotal exige intensidade espiritual genuína e segura, ascética interior e exterior verdadeiramente viril.”.

Spiess (2011) em um estudo sobre seminaristas indica que um dos modos que os seminaristas encontram para construir a masculinidade está no discurso, o qual segundo sua compreensão entende que o gênero se constrói pela linguagem, pelo discurso, mas usam o discurso do comportamento para afirmar uma masculinidade. Uma das formas de masculinidade percebidas por Spiess é aquela no tocante aos que se dedicam as atividades pastorais, aos estudos e apresentam bom comportamento (Spiess, 2011; Benelli, 2003; 2007a). O dado fenomenal desta pesquisa aponta para uma experiência sobre a masculinidade na qual existe uma tônica na dimensão de honra, hombridade, da dimensão valorativa que o homem deve ter. Outro aspecto a que o dado remete é a interiorização de um valor solicitado pela instituição e que o seminarista toma como seu, revelando um aspecto da experiência, sua nota mais fundante, especialmente porque intercepta algo que esteja no bojo da consciência, a consciência de si mesmo, a autoconsciência, como auto-apreensão interna e qualitativa de auto-aspectos do self (Nascimento, 2008; Chalmers, 1996).

As categorias, nesse estudo, parecem se distribuir por entre as etapas de formação. A dicotomia entre os elementos de dificuldade, de renúncia e a felicidade em serem seminaristas salta aos olhos durante o período do Propedêutico; também no tocante a masculinidade esse período mostra uma tendência a afirmação. $\mathrm{O}$ relato dos seminaristas do período do curso de Filosofia, embora ainda tragam categorias referentes as dificuldades do seminário e sua felicidade em ser seminarista, no entanto acentua o aspecto da formação presbiteral, como também o reconhecimento da própria vocação. Por fim, os seminaristas da etapa de Teologia relatam bem menos os aspectos referentes a dificuldade/renúncia e se voltam para a dimensão do reconhecimento da própria vocação. Independente das ênfases significantes, a formação presbiteral é experienciada e significada enquanto objeto na consciência dos seminaristas como: 1. Seminário: lugar de dificuldade/renúncia; 2. Felicidade em ser seminarista; 3. Reconhecimento/discernimento da vocação; 4. Seminário como etapa/lugar de aprendizado; e, 5. Masculinidade/valor, sendo esta síntese fenomenológica a encontrada neste estudo a partir da metodologia fenomenológica empregada.

\section{Considerações finais}

A formação presbiteral acontece em uma conjuntura na qual a formação da subjetividade é objetivo principal e sua conformação aos princípios que coadunam os valores morais e dogmáticos. Entretanto, a experiência interna do ser seminarista católico mostra um movimento psíquico, no qual existe uma tendência para se conformar com as demandas institucionais, e por outro a conservação de aspectos muito particulares da subjetividade.

Os elementos apontados nos achados de pesquisa corroboram a hipótese assumida inicialmente e vão ao encontro da questão levantada por esse estudo que permite acessar a experiência formativa do futuro presbítero. As categorias temáticas estão no tocante a experiência interna, das imagens mentais, do pensamento e das emoções. Contudo é importante salientar que essa pesquisa não esgota a temática e nem pretende indicar que esses dados sejam uma verdade absoluta. O diálogo da teoria psicológica com a literatura da formação presbiteral e das orientações emanadas da Igreja Católica aponta uma profícua reflexão que reverbere positivamente nas dinâmicas institucionais e, sobretudo na formação presbiteral.

Além do fomento que essa pesquisa permite à formação presbiteral, sobretudo no tocante a qualidade de vida, e na compreensão da formação presbiteral a partir de um olhar psicológico salutar para psicologia clínica e cognitiva, este estudo possui seu valor significativo em 
razão de explorar um lócus de pesquisa relativamente novo pois traz uma nova perspectiva em investigar a formação presbiteral à luz dos estudos sobre a consciência, que em si mesmos, são escassos na literatura nacional, e na sua contraparte metodológica, o uso da análise fenomenal como instrumento para acesso da experiência da formação presbiteral, em especial pelo aspecto novo que essa perspectiva traz. Embora esse trabalho seja de matriz fenomenal, é importante salientar que esse dado qualitativo não esgota a riqueza da experiência dos participantes e não encerra as possibilidades metodológicas que em si mesmas e na interface desses dados fenomenais possibilitarão em estudos futuros descortinar um mais vasto entendimento do fenômeno.

\section{Referências}

Amatuzzi, M. M. (2007). Experiência: um termo chave para a Psicologia. Memorandum, 13, 08-15. Recuperado em Abril de 2015, de <http://www.fafich.ufmg.br/ memorandum/ a13/01Amatuzzi.pdf $>$.

Baungart, T. A. A., \& Amatuzzi, M. M. (2013). Grupo de crescimento psicológico na formação sacerdotal: pertinência e possibilidades. Gerais: Revista Interinstitucional de Psicologia, 6 (2), 266-281.

Benelli, S. J. (2003). Pescadores de homens: a produção da subjetividade no contexto institucional de um seminário católico (Dissertação de Mestrado). Universidade Estadual Paulista, Assis.

Benelli, S. J. (2006). O seminário católico e a formação sacerdotal: um estudo psicossocial. Psicologia USP, 17 (3), 145-182.

Benelli, S. J. (2007a). A produção da subjetividade na formação contemporânea na formação do clero (Tese de Doutorado). Universidade de São Paulo, São Paulo.

Benelli, S. J. (2007b). Operadores e paradigmas eclesiais na formação do clero. Fragmentos de Cultura, 17 (11-12), 1095-1117.

Benelli, S. J. (2007c). Análise Institucional de um seminário católico e da formação sacerdotal. Revista de Psicologia da UNESP, 6 (1), 13-30. Recuperado em Abril de 2015, de < http://www2.assis.unesp.br/revpsico/index.php/revista/article/ viewFile/34/59>.

Benelli, S. J. (2008). Estudo psicossocial de um seminário teológico: a formação do clero católico em análise. Estudos de Psicologia, 13 (3), 203-211. Recuperado em Abril de 2015, de < http://www.scielo.br/pdf/epsic/v13n3/a03v13n3.pdf> .

Boemer, M. R. (1994). A condução de estudos segundo a metodologia de investigação fenomenológica. Revista Latino-americana de Enfermagem, 2 (1), 83-94.

Borgoni, D. (2011). A experiência consciente em David Chalmers. Filogênese, 4 (1), 97-108. Recuperado em Abril de 2015, de https://www.marilia.unesp.br/Home/RevistasEletronicas/FILOGENESE/DanielBorgoni.pdf>.
Carruthers, P. (2002). The cognitive functions of language. Behavioral and Brain Sciences, 25 (6), 657-74. Recuperado em Abril de 2015, de < http://faculty.philosophy.umd.edu/pcarruthers/Cognitive-language.htm $>$.

Chalmers, D. J. (1996). The Conscious Mind. New York: Oxford University Press.

Chalmers, D. J. (2010). The Character of Consciousness. Oxford: Oxford University Press.

Conferência Nacional dos Bispos do Brasil - CNBB (2010). Diretrizes para a formação dos presbíteros da Igreja no Brasil. 1. ed. Brasília: Edições CNBB.

Cott, C.; \& Rock, A. (2008). Phenomenology of N,N-Dimethyltryptamine Use: A Thematic Analysis. Journal of Scientific Exploration, 22 (3), 359-370.

Castro, T. G. D., \& Gomes, W. B. (2011). Aplicações do método fenomenológico à pesquisa em psicologia: tradições e tendências. Estudos de psicologia (Campinas). Vol. 28, n. 2 (abr./ jun. 2011), p. 153-161.

Feijoo, A. M. L. C., \& Mattar, C. M. (2015). A Fenomenologia como Método de Investigação nas Filosofias da Existência e na Psicologia. Psicologia: Teoria e Pesquisa, 30 (4), 441-447.

Gaspar, Y. E., \& Mahfoud, M. (2006). Uma leitura histórica do conceito de experiência e uma proposta de compreensão do ser humano em seu caráter essencial: experiência elementar e suas implicações para a psicologia. Anais do III Seminário Internacional de Pesquisa e Estudos Qualitativos \& VEncontro de Fenomenologia e Análise do Existir em São Bernardo do Campo. São Paulo: SE\&PQ. Recuperado em Abril de 2015, de $<$ http://www.sepq.org.br/IIIsipeq/anais/pdfs/pchf11.pdf>.

Giorgi, A. (2006). Difficulties encountered in the application of the phenomenological method in the social sciences. Análise Psicológica, 24 (3), 353-361.

Giussani, L. (1997). Il senso religioso. Milano: Rizzoli.

Giussani, L. (2000). L'autocoscienza del cosmo. Milano: Biblioteca Universale Rizzoli.

Goffman, E. (1974). Manicômios, prisões e conventos. São Paulo: Perspectiva.

Heavey, C. L., \& Hurlburt, R. T. (2008). The phenomena of inner experience. Consciousness and Cognition, 17 (3), 798-810.

Hurlburt, R. T. (2009). Iteratively Apprehending Pristine Experience. Journal of Consciousness Studies, 16 (10-12), 156188. Recuperado em Abril de 2015, de https://faculty.unlv. edu/hurlburt/hurlburt-2009c.pdf>.

Igreja Católica (2003). Catecismo da Igreja Católica. São Paulo: Loyola.

Igreja Católica (2005). Instrução sobre os critérios de discernimento vocacional acerca das pessoas com tendências homossexuais e da sua admissão ao Seminário e às Ordens Sacras. Congregazione per L’Educazione Cattolica. Recuperado em Abril de 2015, de < http://www.conferenciaepiscopal. es/images/stories/documentos/santasede/2005Discernimie ntoHomosexualidad.pdf $>$. 
Igreja Católica (1965). Optatam Totius. Decreto do Concílio Vaticano II, 1965. Recuperado em Abril de 2015, de <http:// www.vatican.va/archive/hist_councils/ii_vatican_council/documents/vat-ii_decree_19651028_optatam-totius_ po.html>.

Igreja Católica (2008). Orientações para a utilização das competências psicológicas na admissão e na formação dos candidatos ao sacerdócio. Congregazione per L’Educazione Cattolica. Recuperado em Abril de 2015, de <http:// www.conferenciaepiscopal.es/images/stories/documentos/ santasede/2008Psicologia.pdf $>$.

Igreja Católica (1970). Ratio Fundamentalis Institutionis Sacerdotalis. Sacra. Recuperado em Abril de 2015, de <http://www. osib.org.br/documentos/doc_details/2-ratio-fundamentalis-institutionis-sacerdotalis.html $>$.

João Paulo II. (1992). Pastores Dabo Vobis. Exortação Apostólica, 1992. Recuperado em Abril de 2015, de <http://www. vatican.va/holy_father/john_paul_ii/apost_exhortations/ documents/hf_jp-ii_exh_25031992_pastores-dabo-vobis po.html>.

Kriegel, U. (2006). Consciousness, Theories of. Philosophy Compass, 1 (1), 58-64.

Meschiatti, J. E. (2007). Trabalhadores da vinha: estudo sobre a formação do clero - O Seminário Católico antes e depois do Concilio Vaticano II (Tese de Doutorado). Universidade Estadual de Campinas, Campinas.

Moreira, V. (2004). O método fenomenológico de Merleau-Ponty como ferramenta crítica na pesquisa em psicopatologia. Psicologia: Reflexão e crítica, 17 (3), 447-456.

Morin, A. (2005). Possible links between self-awareness and inner speech: Theoretical background, underlying mechanisms, and empirical evidence. Journal of Consciousness Studies, 12 (4-5), 115-134. Recuperado em Abril de 2015, de <http://citeseerx.ist.psu.edu/viewdoc/download?doi=1 0.1.1.96.2675\&rep $=$ rep1\&type $=p d f>$.

Nascimento, A. M. (2008). Autoconsciência Situacional, Imagens Mentais, Religiosidade e Estados Incomuns da Consciência: um estudo sociocognitivo (Tese de Doutorado). Universidade Federal de Pernambuco, Recife.

Nascimento, A. M., Griz, C. A. S. \& Vieira, E. S. (2013). Experiência Interna durante a Prece [Trabalho completo]. In Laboratório de Estudos da Autoconsciência, Consciência, Cognição de Alta Ordem e Self (Org.), Anais do I Simpósio de Pesquisa LACCOS Autoconsciência e Cognição: Ressurgências Metodológicas, v. 1. (p. 20-23). Recife: LACCOS.

Paulo VI. (1967). Sacerdotalis Caelibatus. Carta Encíclica, 1967. Recuperado em Abril de 2015, de < http://www.vatican. va/holy_father/paul_vi/encyclicals/documents/hf_p-vi_ enc_24061967_sacerdotalis_po.html>.

Rocha, C. L. R. (1991). "Muitos são os chamados mas poucos os escolhidos": um estudo sobre a vocação sacerdotal (Dissertação de Mestrado). Universidade Estadual de Campinas, Campinas.

Santos, E. A. (2016). Representações sociais da sexualidade: a construção da sexualidade em seminaristas e padres (Te- se de Doutorado). Universidade Federal do Rio Grande do Sul, Porto Alegre.

Schneider, S. (2012). Why property dualists must reject substance physicalism. Philosophical Studies, 157 (1), 61-76. Recuperado em Abril de 2015, de <http://schneiderwebsite. com/Susan_Schneiders_Website/Research_files/SchneiderPropertyDualism.pdf $>$.

Spiess, M. A. (2011). Gênero, celibato e seminaristas: reflexões sobre sexualidade num Seminário Católico. Anais do XII Simpósio da ABHR, 31/05 - 03/06 de 2011, Juiz de Fora (MG), GT 05: Gênero, ciências e religiões, 12 (1), 01-18. Recuperado em Abril de 2015, de < http://www.abhr.org.br/plura/ojs/ index.php/anais/article/view/228 $>$.

Spiess, M. A. (2012). Futuros Sacerdotes do Senhor: a decisão vocacional entre seminaristas em Santa Catarina (Dissertação de Mestrado). Universidade Federal de Paraná, Curitiba.

Velmans, M. (2009). How to Define Consciousness - And How Not to Define Consciousness. Journal of Consciousness Studies, 16 (5), 139-156.

Rafael Amorim de Paula - Tem Bacharelado e Formação em Psicologia em Psicologia pela Universidade Federal de Pernambuco, Membro do Laboratório de Autoconsciência, Consciência, Cognição de alta ordem e Self (LACCOS).

Alexsandro Medeiros do Nascimento - Possui Bacharelado em Psicologia pela Universidade Federal do Rio Grande do Norte, Mestrado e Doutorado em Psicologia Cognitiva pela Universidade Federal de Pernambuco. Realizou Estágio de Pós-Doutorado na Universidade Federal de Pernambuco (UFPE), Área: Psicologia Cognitiva. Atualmente é Professor Adjunto I da Universidade Federal de Pernambuco, Professor Permanente do Programa de Pós-Graduação em Psicologia Cognitiva da UFPE e Coordenador do Laboratório de Estudos da Autoconsciência, Consciência, Cognição de Alta Ordem e Self (LACCOS/UFPE). Endereço Institucional: Av. Acadêmico Hélio Ramos, s/n - Centro de Filosofia e Ciências Humanas (CFCH), $8^{\circ}$ Andar - Programa de Pós-Graduação em Psicologia Cognitiva - Recife - 50670-901 PE Brasil. Email: alexmeden@hotmail.com

Recebido em 23.05.2015 Primeira Decisão Editorial em 01.03.2016 Aceito em 21.08.2017 